\title{
Perception of three-dimensional form by human infants
}

\author{
PHILIP J. KELLMAN \\ Swarthmore College, Swarthmore, Pennsylvania
}

\begin{abstract}
Human adults can perceive the three-dimensional form of an object from single views or from the continuously transforming two-dimensional projections of an object rotating in depth. The present work reports that 16 -week-old infants can perceive three-dimensional form from transforming optical projections, but not from single or multiple static views of an object. In a habituation-of-looking-time procedure, infants in a kinetic condition were shown videotapes of one of two three-dimensional objects continuously rotating, on alternate trials, around two different axes of rotation in depth. Infants in two other conditions saw successive static views taken from the same rotation sequences. After habituation, perception of three-dimensional form was tested by presenting the same three-dimensional form moving around a new axis of rotation in depth and a different three-dimensional form moving around the same, new axis. Infants shown continuously transforming displays generalized habituation to the same object and dishabituated dramatically to the new object, whereas infants in the two static conditions showed no differential responding to the test objects as a function of habituation object. Kinetic information seems to be primary in the development of three-dimensional form perception.
\end{abstract}

Perceiving the three-dimensional forms of objects is central to human thought and behavior. Many important properties of objects depend on their forms; moreover, when other properties of objects concern us, we may still detect and recognize these objects by their forms. The visual sense predominates in enabling us to perceive threedimensional form, at a distance and with great precision. How these abilities originate in the life of a human perceiver is currently not well understood. This question, specifically, the origins of visual form perception abilities in early infancy, is the subject of the present research.

Adult perception of form occurs under diverse circumstances, and similar diversity has characterized theories of the origins of form perception. Adults often perceive the three-dimensional form of an object from a single viewpoint. This fact is consistent with the old notion that one view calls up previously remembered views from other vantage points, and that these associated views together constitute the form (Helmholtz, 1866/1925; Mill, 1865/1968; cf. Hebb, 1949). Adults may also perceive the whole form of an unfamiliar object from a single view, suggesting reliance on rules about object regularities (Michotte, Thines, \& Crabbe, 1964; Wertheimer, 1923/1958). Some recent analyses, however, suggest that the fundamental process in form perception does not in-

A report of this research was presented at the Biennial Meeting of the Society for Research in Child Development in April 1983. This research was supported by NSF Grant BNS-8210110, by a Swarthmore College faculty research grant, and by a Summer Research Grant from the Swarthmore College Chapter of Sigma Xi. I thank Robert Becklen, Ellen Dye, Kenneth Short, and Hans Wallach for helpful discussions. Requests for reprints should be sent to Philip J. Kellman, Department of Psychology, Swarthmore College, Swarthmore, PA 19081. volve such rules, but depends on the pickup of information from optical transformations, given by object or observer movement (Gibson, 1966, 1979; Johansson, 1970). Mathematically, the continuously transforming projection from a rotating object contains invariant projective geometric properties unique to that object (Gibson, 1979; Braunstein, 1976). Perceptually, human adults readily utilize transforming projections to perceive accurate form and depth (Braunstein, 1976; Gibson, 1979; Wallach \& O'Connell, 1953).

Accounts of the origins of form perception abilities have diverged sharply over the contributions of innate endowment or maturation as opposed to learning. Rules of object perception, for example, have been claimed to reflect the intrinsic functioning of the nervous system (Koffka, 1935) or, in contrasting views, to be derived from experience (Brunswik, 1956; Piaget, 1954, 1977). Much recent discussion has focused on the suggestion that the detection of invariant properties from optical transformations may be accomplished by perceptual mechanisms that are products of evolution (Gibson, 1966, 1979; Johansson, 1970; Shepard, 1982). Even some perceptual theorists who emphasize the role of learning in perception have suggested that perceiving form from motion information may be an innate ability on which subsequent learning may be based (Wallach \& O'Connell, 1953).

Little previous research has addressed these conjectures directly, by studying human infants. Perception of invariant two-dimensional shape at different slants has been investigated by Bower (1966) and by Caron, Caron, and Carlson $(1978,1979)$. The latter study resolved some difficulties of earlier work and provided evidence that 12week-old infants can detect invariant two-dimensional shape despite differences in slant. 
While perceiving the invariance of static planar figures at varying slants may be related, or even prerequisite, to perceiving the three-dimensional forms of objects, it is not logically sufficient. As an empirical matter, there is little evidence for early three-dimensional form perception. One of the only studies of three-dimensional form perception in the first several months of life (Day \& McKenzie, 1973) reported equal rates of habituation of looking time by 6- to 16 -week-olds to a solid cube in a single orientation and to multiple stationary views of the cube, whereas no habituation was observed in a group shown pictures of the cube in multiple orientations. These results could have been due to perception of constant form in the solid condition; however, they might simply indicate that infants habituate more slowly to photographs than to real objects. A later study (Cook, Field, \& Griffiths, 1978 ) is consistent with the latter interpretation, suggesting that the original result did not depend on perception of three-dimensional form. Recently, Owsley (1983) provided some evidence of discrimination between two objects based on kinetic information. After habituation, infants given monocular kinetic information dishabituated more in subsequent binocular, stationary viewing to a new object than to the old one. Perception of overall threedimensional form could not be assessed in this study because only two facets of the objects were exposed. The results seem best interpreted in terms of discrimination of some (probably three-dimensional) feature of the objects, perhaps the angle of intersection of the two facets, rather than perception of overall form. This interpretation is consistent with other data. Although Owsley reported transfer from kinetic information to stereoscopic information, others (Kellman \& Short, 1984; Ruff, 1978) have found even multiple, static binocular views to be inadequate to allow perception of overall form at this age.

The present study provides evidence that young infants perceive the three-dimensional forms of objects from information in optical transformations, but not from static views of objects.

A major challenge in attempting to study infants' perception of three-dimensional form is to isolate responses to overall form from responses to features of proximal stimulus (two-dimensional) patterns. If an object is presented to an infant and later presented again in the same way, it may be recognized and distinguished from another object simply on the basis of its characteristics as a two-dimensional projection. In the present investigation, a method was devised to test for perception of invariant three-dimensional form across widely varying proximal stimuli. The method made use of the fact that projective geometric information specifying an object's three-dimensional form may be given by rotation around almost any axis, provided there is some component of rotation in depth. With suitably chosen objects and axes, rotation around each axis will produce a quite different set of patterns projected to the eyes. By changing the axis of rotation, therefore, one can test for recognition of a given three-dimensional form using particular views (proximal stimuli) that have not been seen before.

Infants' perception was assessed using a habituationof-looking-time procedure (Cohen \& Gelber, 1975; Horowitz, 1974; Tighe \& Leaton, 1976). Repeated presentation of a given visual display typically results in a decline in an infant's looking time, known as habituation. Afterward, presentation of the same or a similar display will, on average, meet with low looking times, while presentation of a novel display will typically evoke dishabituation, that is, recovery of looking times to higher levels. This method has become the most widely used in studies of infant perception (Cohen, DeLoache, \& Strauss, 1979).

If infants perceive three-dimensional form from information available in continuous optical transformations, habituation to a videotape of an object rotating around one axis might generalize to a videotape of that object rotating around a different axis. Habituation should not generalize to a different three-dimensional form rotating around the new axis. Infants might, however, dishabituate to a change in rotation axis as well as a change in form. To minimize this possibility, two different rotations of the same object were shown on alternate trials in habituation and a third rotation was used in the test trials. This manipulation is analogous to that used by Caron et al. (1979) to isolate responding to shape while minimizing responding to changed slant.

Two other groups served as checks on the method in the kinetic group and also as tests of infants' abilities to perceive three-dimensional form from single or multiple static, two-dimensional views of objects. These groups viewed sequences of photographic slides taken from the rotation cycles. If infants perceive three-dimensional form from any single view or from sequences of static views, then one or both of the control groups was expected to generalize habituation to the familiar object and dishabituate to the novel object.

\section{METHOD}

\section{Subjects}

Seventy-two full-term infants ranging in age from 98 days to 138 days (mean age: 119 days) served as subjects. The subjects were recruited from the western suburbs of Philadelphia by letter and telephone contact with parents, who were identified from newspaper birth announcements. An additional 43 subjects began the experiment but did not complete it, 31 due to fussing, 7 due to equipment failure, and 5 due to experimenter error.

\section{Displays and Apparatus}

The two objects used in the study are pictured in Figure 1. The objects were made of wood, painted orange and always displayed against a homogeneous black background. Two-dimensional views of these two objects were used in all conditions of the experiment to eliminate stereoscopic information about three-dimensional form. In one condition, the objects were shown on videotape continuously rotating in depth; in the other two conditions, multiple static views (photographic slides) were rear-projected onto a translucent screen (see below). Displays of the two objects were made under identical illumination conditions. One 
60-W lightbulb was positioned about $1 \mathrm{~m}$ above, $1.5 \mathrm{~m}$ in front of, and $1 \mathrm{~m}$ to the left of the object; another $60-\mathrm{W}$ bulb was positioned in a corresponding position to the right. A third $60-\mathrm{W}$ bulb was placed about $2 \mathrm{~m}$ in front of the object and $.75 \mathrm{~m}$ below. This arrangement ensured that all facets of the objects oriented toward the observer were visible and that there were noticeable differences in shading among them. In all cases, the displays were presented $61 \mathrm{~cm}$ from the infant, who was seated in a standard infant chair. The rectangular view of each object (see Figure 1) measured $10.2 \times 5.1 \mathrm{~cm}$ on the viewing screen. At the infant's viewing distance, the objects subtended about $9.5^{\circ}$ of visual angle vertically, and about $4.8^{\circ}$ horizontally.

Objects rotated around three axes (continuously in the kinetic condition; static views taken from the rotation sequences were used in the static conditions). The vertical axis attached to the middle of each object's base. The diagonal axis lay in the frontoparallel plane, attached to the middle of one side of each object's base, and was oriented $45^{\circ}$ from the medial and saggital planes. The corner axis extended backward from a rear corner of each object at $45^{\circ}$ from all three planes. The axis in each case was a metal rod painted flat black so as not to be visible on the videotapes or slides. Continuous rotation was accomplished by attaching the axis to an electric motor.

A sheet of white cardboard, which slid along a wooden track, could be interposed between the subjects and the display screen between trials. Curtains along the sides of the table on which subjects were seated kept the removed cardboard sheet and other objects in the room out of sight.

\section{Design}

Each infant was tested in one of three conditions. In the kinetic condition, infants viewed continuously transforming projections given by rotating objects on videotapes. Each complete rotation took $15 \mathrm{sec}$. In one static condition, infants saw 6 views spaced $60^{\circ}$ apart for $2 \mathrm{sec}$ each; a .5-sec blank interval occurred between slides, so that the complete sequence occurred every $15 \mathrm{sec}$. In the other static condition, infants saw 24 views spaced $15^{\circ}$ apart for $1 \mathrm{sec}$ each, also with a .5 -sec interval between slides. ' Whereas the $60^{\circ}$ static condition was comparable to the kinetic condition in terms of viewing time required to see a complete rotation, the $15^{\circ}$ condition aimed to minimize differences between successive views. Adults could detect the three-dimensional form of each object from virtually all of the individual views. Infants in all groups were habituated to views of a single three-dimensional object, with two different axes of rotation used on alternate habituation trials. After habituation, infants' looking times were measured to alternate presentations of the same object in a new axis of rotation and of a different object rotating around the same, new axis. Which object and which rotations were used in the habituation and test periods, as well as which object was shown first in the tests, were completely counterbalanced.

\section{Procedure}

The subjects were tested separately. After a subject was placed in the infant seat, curtains to the sides were arranged to eliminate any view of the room. Parents viewed the experiment from behind the infant and were instructed not to interact with the baby. To begin the study, the videotape machine or slide projector was turned on and the cardboard barrier was slid away. An "infant control" habituation procedure (Horowitz, 1974) was used. After the infant had fixated the display for at least $.5 \mathrm{sec}$, a trial would continue until the infant looked away for 2 continuous seconds, up to a maximum of $60 \mathrm{sec}$ of looking time. The dependent variable on each trial was the looking time accumulated before a look away occurred. At the end of the trial, the cardboard barrier was slid in front of the display screen. An intertrial interval of $8 \mathrm{sec}$ was used on all trials, which allowed changing of displays. Closing and opening of the cardboard screen required an additional 1-2 sec each.

A single object was shown in two different rotations on alternate trials until the criterion of habituation was met. The criterion was a $50 \%$ decrease from a subject's initial looking levels. Looking times on the first two habituation trials were summed; two later, consecutive trials summing to less than half of this value were required to meet the criterion. If total looking time on the first two trials did not exceed $12 \mathrm{sec}$, the habituation criterion was set by the first two consecutive trials that did exceed 12 sec.

Test trials consisted of alternating presentations of the old and the new object, three times each. Both test displays moved around the same axis of rotation, which always differed from the two axes of rotation used in habituation. Test trials were otherwise identical to the habituation trials.

Habituation and test procedures in the two static groups were exactly the same as in the kinetic group, except that successive static views were presented instead of continuous rotations.

Looking time was measured by two trained observers, using pushbutton inputs to a computer. Observers viewed the infant through small holes above and slightly to the sides of the display screen. Observers did not know at any time what display was being presented. Interobserver agreement (proportion of total time that both observers were registering a look or nonlook) averaged .90 and ranged from .77 to .99 . One observer was designated as the primary observer: His or her responses were used by the computer to determine the ends of individual trials and also the habituation period. The primary observer also decided whether to suspend or terminate the experiment if an infant became fussy. A third person changed the displays and opened and closed the display window as signaled by the computer. This person operated the electrical slide-changing button in the static conditions, controlling the 1- or 2 -sec-exposure durations by counting, after extensive training with a

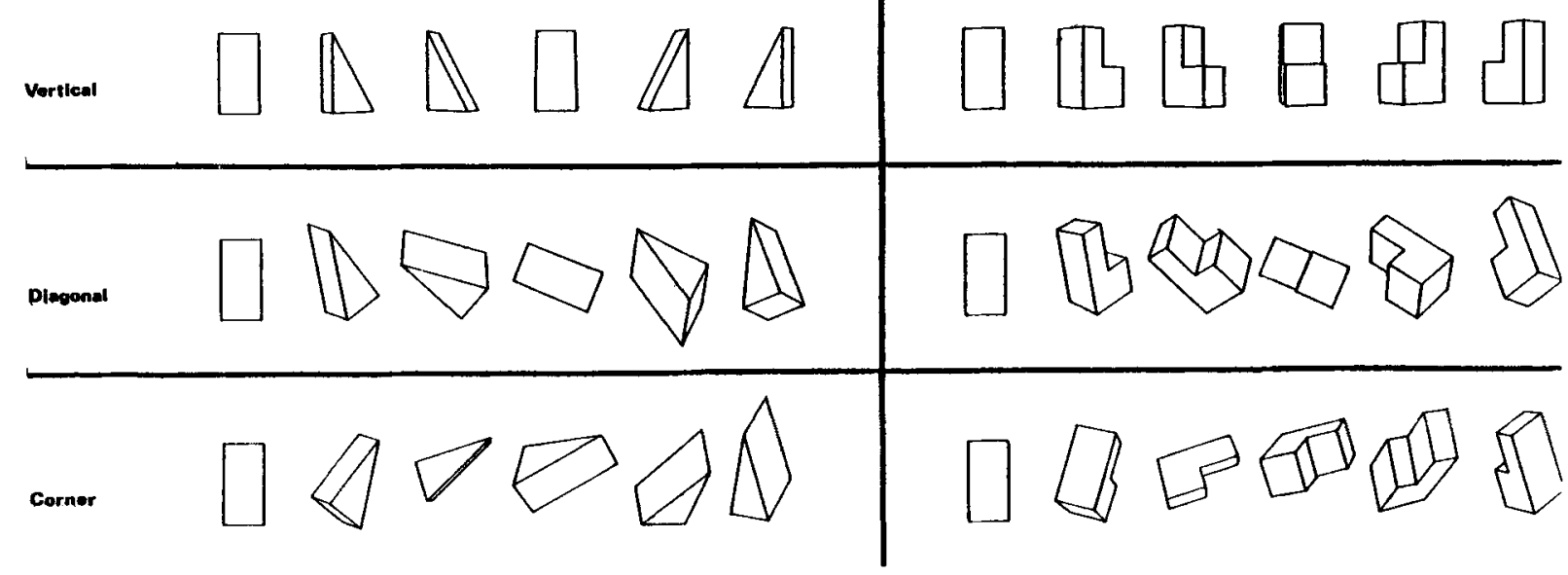

Figure 1. Objects and rotations used in the experiment. Successive views $60^{\circ}$ apart are shown. 
digital stopwatch. At the end of a slide sequence, the operator depressed the tray release button and rotated the slide tray back to the first slide. This step took about $.5 \mathrm{sec}$, as did the normal electrical slide advance.

If an infant showed discomfort, the experiment was stopped temporarily and then resumed if possible. If no habituation criterion had been set, three new trials were required to set it upon resuming. If the criterion had been set but not met, three new trials were required to meet the criterion. If an infant became fretful on the final habituation trial or during the test trials, the experiment was terminated and the subject was replaced. No subject had more than one break during habituation.

\section{Dependent Measures and Data Analyses}

The primary dependent measure was dishabituation, defined as a subject's looking time on the first test trial presentation of each test display minus his/her looking time on the final trial of the habituation period. Preliminary analyses of variance in each group assessed the dishabituation data for main effects and interactions involving which object was shown first in the test period, which rotations were used in habituation, and which of the two habituation rotations was shown first. There were two main analyses of the dishabituation data. First, a 3 (presentation condition) $\times 2$ (habituation object) $\times 2$ (test object) ANOVA was carried out, followed by individual comparisons to ascertain the loci of significant overall effects. Tests of dishabituation levels against the hypothesis of 0 dishabituation were also performed. Secondly, in each group, the number of subjects (out of 24) who showed greater recovery of looking time to the new object than to the old object on the first test trial was compared to the null hypothesis (50\%) by binomial test. Analyses of looking times over all three test trials, without correction for final habituation levels, were also carried out. Finally, several characteristics of the habituation period were measured, including looking time per habituation trials, duration of looking on the first habituation trial, and number of trials to meet the habituation criterion.

\section{RESULTS}

\section{Preliminary Analyses}

Preliminary analyses indicated no significant effects or interactions involving which object was shown first in test trials and no effects of specific rotation axes (all Fs $<1.75$, n.s.).

\section{Dishabituation Analyses}

Table 1 shows looking time on the final habituation trial and looking time on the first exposure of the two test objects by group, habituation object, and test object. A threeway ANOVA with factors of condition (kinetic, $15^{\circ}$ static, and $60^{\circ}$ static), habituation object ( 1 and 2 ), and test object ( 1 and 2 ) was carried out on the dishabituation data (first test trial looking time minus final habituation trial looking time). There was a marginally significant main

Table 1

Looking Time on First Test Trial and Final Habituation Trial by Group, Habituation Object, and Test Object

\begin{tabular}{lcccc}
\hline & & \multicolumn{2}{c}{ Looking Time (in Seconds) } \\
\cline { 3 - 5 } & & $\begin{array}{c}\text { Final } \\
\text { Habituation }\end{array}$ & \multicolumn{2}{c}{ Test Object } \\
\cline { 3 - 5 } Group & Habituated to: & Trial & Object 1 & Object 2 \\
\hline Kinetic & Object 1 & 6.8 & 6.5 & 18.2 \\
& Object 2 & 5.8 & 17.2 & 8.8 \\
$15^{\circ}$ Static & Object 1 & 3.6 & 10.1 & 10.3 \\
& Object 2 & 4.4 & 6.0 & 8.3 \\
$60^{\circ}$ Static & Object 1 & 4.0 & 3.7 & 4.6 \\
& Object 2 & 2.7 & 4.0 & 4.9 \\
\hline
\end{tabular}

effect of condition $[F(2,66)=2.93, .05<p<.10]$, a significant interaction of habituation and test object $[\mathrm{F}(1,66)=5.33, \mathrm{p}<.025]$, and a three-way interaction of condition, habituation object, and test object $[\mathrm{F}(2,66)$ $=7.54, \mathrm{p}<.005]$. There were no other reliable main effects or interactions. Individual comparisons showed that the effect of condition was due to higher total recovery (to both test objects combined) in the kinetic and $15^{\circ}$ static groups than in the $60^{\circ}$ static group. While the kinetic and $15^{\circ}$ group did not differ in total recovery $[\mathrm{t}(46)=.62$, n.s.], the kinetic group exceeded the $60^{\circ}$ group [t(46) $=$ $2.61, \mathrm{p}<.01]$, as did the $15^{\circ}$ static group $[\mathrm{t}(46)=1.93$, $\mathrm{p}<.05$, one-tailed]. Further comparisons showed both of the interaction effects to be due to differences within the kinetic group. Kinetic group infants who were habituated to object 1 recovered significantly more to object 2 than to object $1[t(11)=2.90, p<.01]$, whereas those habituated to object 2 recovered significantly more to object $1[t(11)=2.86, p<.01]$. Twenty-three of the 24 infants in the kinetic group looked longer at the new object than at the old object on the first test presentation of each $(p<.001$, binomial test). The static groups showed no significant differences in dishabituation to the two test objects as a function of habituation object [all ts $(11)<.60$, n.s.]. In both static groups, 14 of the 24 infants looked longer at the new object than at the old object on the first test trial (n.s.).

Absolute recovery levels were assessed in each group by comparing recovery scores to the old and new objects to 0 . Figure 2 shows looking times for the three groups to the old and new objects in the test trials. In the kinetic group, recovery to the old object did not reliably exceed $0[\mathrm{t}(23)=.96, \mathrm{n} . \mathrm{s}$.$] , whereas recovery to the new object$ was much greater than $0[\mathrm{t}(23)=3.80, \mathrm{p}<.001]$. The $15^{\circ}$ static group showed recovery greater than 0 for both the old object $[\mathrm{t}(23)=2.08, \mathrm{p}<.025]$ and the new object $[\mathrm{t}(23)=1.99, \mathrm{p}<.05]$, whereas the $60^{\circ}$ static group did not show recovery reliably greater than 0 to the old object $[\mathrm{t}(23)=.92$, n.s.] or the new object $[\mathrm{t}(23)$ $=1.16$, n.s.]. Comparisons across groups indicated that the kinetic group and the $60^{\circ}$ static group did not differ in recovery to the old object $[\mathrm{t}(46)=.23$, n.s.], but the kinetic group showed greater recovery to the new object $[t(46)=3.39, p<.001]$. The kinetic group also exceeded the $15^{\circ}$ static group in recovery to the new object $[t(46)=2.01, p<.05]$, but was marginally lower than the $15^{\circ}$ group in recovery to the old object $[\mathrm{t}(46)=1.37$, $.05<\mathrm{p}<.10]$. The $15^{\circ}$ group marginally exceeded the $60^{\circ}$ group in recovery to both the old $[\mathrm{t}(46)=1.59$, $.05<\mathrm{p}<.10]$ and the new object $[\mathrm{t}(46)=1.46$, $.05<\mathrm{p}<.10]$.

Analyses of looking time over all three test trials, without correction for final habituation levels, supported the main findings above.

\section{Habituation Analyses}

Looking times during the habituation trials for the three groups are shown in Figure 2. No differences among groups were found in the number of trials required to 
A

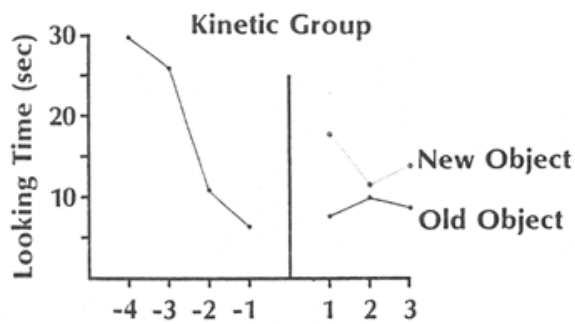

B

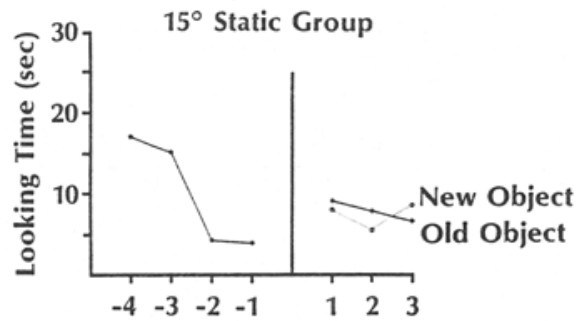

C

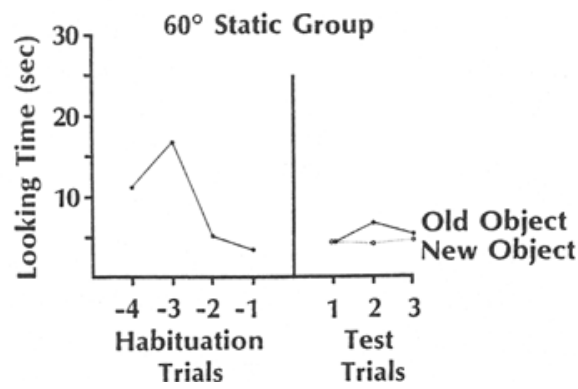

Figure 2. Looking time during habituation and test trials in the (a) kinetic group, (b) $15^{\circ}$ static group, and (c) $60^{\circ}$ static group. Habituation trials are numbered backward from the trial on which the habituation criterion was met. Test trials are designated according to whether the object presented was the same as the one shown in habituation ("old object") or not ("new object").

reach habituation criterion, but the kinetic group exceeded the two static groups in looking time per trial during the habituation period. The finding of longer looking times to moving displays is consistent with many previous reports (Carpenter, 1974; Volkmann \& Dobson, 1976).

\section{Additional Analyses}

It was possible that perception of three-dimensional form required seeing, on some trial, a certain critical amount of the rotation sequence, and that this occurred more often in the kinetic condition, in which looking times were longer. This conjecture is implausible given two aspects of the data. First, there was no significant correlation between subjects' mean looking times on habituation trials and looking time differences in the test trials for any of the three groups [all rs $<.11$, n.s.]. Second, subjects in the kinetic group and each static group who showed comparable mean looking times on habituation trials were compared for differences in dishabituation to the old and new objects in the test trials. The subset of the kinetic group (mean habituation look, $12.5 \mathrm{sec}$; range, 5.8-19.4 sec; $\mathrm{N}=14$ ) dishabituated more to the new object $[t(13)=2.43, p<.025]$, but neither the $15^{\circ}$ static group (mean, $14.4 \mathrm{sec}$; range, 8.2-31.7 sec; $\mathrm{N}=15$ ) nor the $60^{\circ}$ static group (mean, $13.7 \mathrm{sec}$; range, 8.2-39.1 sec; $\mathrm{N}=10$ ) showed any reliable difference (both ts $<.44$, n.s.). Direct comparisons between groups showed that the subset of the $15^{\circ}$ static condition differed reliably from that of the kinetic group in its dishabituation pattern $[t(27)$ $=1.95, \mathrm{p}<.05]$. The subset of the $60^{\circ}$ static condition also differed reliably from the kinetic group $[\mathrm{t}(22)=2.14$, $\mathrm{p}<.025]$. Evidently, the group differences in this study depended on qualitative differences in the information given by motion and static views, not on viewing time.

\section{DISCUSSION}

Young infants seem to perceive the three-dimensional forms of objects from kinetic information. After habituation to continuously transforming projections of a single three-dimensional object, infants generalized habituation to the same object in a new rotation, and they dishabituated greatly to a different three-dimensional form in the same, new rotation. In contrast, neither of the static presentation conditions led to greater recovery to the novel form after habituation.

The results in the static conditions constrain interpretation of the kinetic condition in two ways. First, information in continuous transformations seems crucial for three-dimensional form perception in this situation. Even closely spaced static views did not lead to form discrimination. Moreover, analyses of the relation of form discrimination to habituation looking times suggest that this failure does not have an attentional explanation; single or multiple static views seem to be ineffective as information for infants about whole form. This conclusion is consistent with other recent work on form (Kellman \& Short, 1984; Owsley, 1983; Ruff, 1978), and also with research indicating the relatively late onset of pictorial depth perception (Yonas, Cleaves, \& Pettersen, 1978). Secondly, the lack of an effect in the static conditions suggests that generalization of habituation to the old object and discrimination of the new object in the kinetic condition must have been based on three-dimensional form, not on the proximal stimulus characteristics of the displays presented. Any features common to various projections of a given object should have been discernible from static views as well as from continuously transforming displays. It appears that the use of different rotation axes with the same three-dimensional object successfully isolated responses to overall form in the kinetic condition, and that form was not perceived in the static conditions.

Infants in the static groups probably perceived sequences of two-dimensional patterns. Numerous studies indicate that infants of this age can discriminate among different two-dimensional patterns (for a review, see Cohen et al., 1979). In the present study, the static views 
spaced $60^{\circ}$ apart probably appeared quite discrepant from one another. If so, the only consistent expectations to arise during habituation might have involved the relatively consistent size and color of the displays. This would account for the minimal recovery to both the old and new objects after habituation, since both had projections of similar size and color. The greater recovery to both objects in the $15^{\circ}$ condition might indicate that the closer spacing of views led to extraction of some surface features common to many, or at least some, of the views in a given sequence. Such expectations about recurrent proximal stimulus features would have been disconfirmed by test trials with the old object in a new rotation and also with the new object.

These findings are consistent with the hypothesis that the ability to detect form from motion information is innate. It remains possible that this ability has been learned in the first few months of life. Such learning would seem to require, however, connecting motion patterns with some other source of information about form. It is unclear what information this could be, since infants at this age do not seem to perceive three-dimensional form from static views and are not in general capable of skillful manual exploration (Bower, 1979; von Hofsten, 1984).

The results also suggest that adults' abilities to perceive three-dimensional form from configural and shading cues in single views develops later than the first 4 months of life. This conclusion is tentative inasmuch as photographic slides were used in this experiment. Infants' depthperception abilities (Fox, Aslin, Shea, \& Dumais, 1980) might have accurately registered the projection screen as flat. That this possible cue conflict did not preclude form perception in the kinetic condition does not rule out its influence in the static conditions. However, other research, in which real objects were presented, suggests that infants as old as 6 months do not perceive threedimensional form from multiple stationary views of an object (Cook et al., 1978; Kellman \& Short, 1984; Ruff, 1978).

The primary process in human three-dimensional form perception seems to be the detection of information in continuous optical transformations; such information may be available early in life to an observer being moved through stationary environments, or to a stationary observer viewing moving objects. The use of static information to perceive form may develop later.

\section{REFERENCES}

BOWER, T. G. R. (1966). Slant perception and shape constancy in infants. Science, 151, 832-834.

BowER, T. G. R. (1979). Human development. San Francisco: Freeman. Braunstein, M. (1976). Depth perception through motion. New York: Academic Press.

Brunswik, E. (1956). Perception and the representative design of psychological experiments. Berkeley: University of California Press.

Caron, A., Caron, R., Carlson, V. (1978). Do infants see objects or retinal images? Shape constancy revisited. Infant Behavior \& Development, 1, 229-243.

Caron, A., Caron, R., \& Carlson, V. (1979). Infant perception of the invariant shape of objects varying in slant. Child Development, 50, 716-721.
CARPENTER, G. C. (1974). Visual regard of moving and stationary faces in early infancy. Merrill-Palmer Quarterly, 11, 182-193.

Cohen, L., DeLoache, J., \& Strauss, M. (1979). Infant visual perception. In J. Osofsky (Ed.), Handbook of infant development. New York: Wiley.

Cohen, L., \& Gelber, E. (1975). Infant visual memory. In L. Cohen \& P. Salapatek (Eds.), Infant perception: From sensation to cognition (Vol. 1). New York: Academic Press.

CoOK, M., FIELD, J., \& GRIFFTThs, K. (1978). The perception of solid form in early infancy. Child Development, 49, 866-869.

DAY, R., \& McKenzIE, B. (1973). Perceptual shape constancy in early infancy. Perception, 2, 315-320.

Fox, R., Aslin, R. N., Shea, S. L., \& Dumais, S. T. (1980). Stereopsis in human infants. Science, 207, 323-324.

Grason, J. J. (1966). The senses considered as perceptual systems. Boston: Houghton-Mifflin.

GiBson, J. J. (1979). The ecological approach to visual perception. Boston: Houghton-Mifflin.

HEBB, D. O. (1949). The organization of behavior: A neuropsychological theory. New York: Wiley.

HeLmholtz, H. von. (1925). Handbook of physiological optics (Vol. 3) (J. P. S. Southall, trans.). New York: Optical Society of America. (Original work published 1866)

Horowitz, F. D. (1974). Visual attention, auditory stimulation and language discrimination. Monographs of the Society for Research in Child Development, 39, 5-6.

Johansson, G. (1970). On theories for visual space perception. Scandinavian Journal of Psychology, 11, 67-74.

Kellman, P., \& ShORT, K. (1984). Limitations of early threedimensional form perception. Manuscript in preparation.

KoffKA, K. (1935). Principles of Gestalt psychology. New York: Harcourt.

Michotte, A., Thines, G., \& Crabbe, G. (1964). Les complements amodaux des structures perceptives. In Studia psychologica. Louvain: Publications Universitaires de Louvain.

MiLL, J. S. (1968). An examination of Sir William Hamilton's philosophy. In R. J. Herrnstein \& E. G. Boring (Eds.), A sourcebook in the history of psychology (pp. 182-188). Cambridge, MA: Harvard University Press. (Original book published 1865)

OWSLEY, C. (1983). The role of motion in infants' perception of solid shape. Perception, 12, 707-718.

Piaget, J. (1954). The construction of reality in the child. New York: Basic Books.

Piaget, J. (1977). The development of thought. New York: Viking Press.

RUFF, H. (1978). Infant recognition of the invariant form of objects. Child Development, 49, 293-306.

SHEPARD, R. (1982). Perceptual and analogical bases of cognition. In J. Mehler, E. Walker, \& M. Garrett (Eds.), Perspectives on mental representation. Hillsdale, NJ: Erlbaum.

Tighe, T. J., \& Leaton, R. N. (Eds.) (1976). Habituation: Perspectives from child development, animal behavior and neurophysiology. Hillsdale, NJ: Erlbaum.

Volkmann, F. C., \& DoBson, M. V. (1976). Infant responses of ocular fixation to moving stimuli. Journal of Experimental Child Psychology, 22, 86-99.

voN HoFsten, C. (1984). Developmental changes in the organization of prereaching movements. Developmental Psychology, 20, 378-388.

WALLACH, H., O'CONNELL, D. (1953). The kinetic depth effect. Journal of Experimental Psychology, 45, 205-217.

WerTHEImer, M. (1958). Principles of perceptual organization. In D. C. Beardslee \& M. Wertheimer (Eds.), Readings in perception. Princeton, NJ: Van Nostrand. (Original work published in German, 1923)

Yonas, A., Cleaves, W., \& Pettersen, L. (1978). Development of sensitivity to pictorial depth. Science, 200, 77-79.

\section{NOTE}

1. No apparent motion between successive slides was perceived by adults with the $.5-\mathrm{sec}$ blank interval used in the two static conditions.

(Manuscript received May 29, 1984; revision accepted for publication August 31, 1984.) 